\title{
Characterization of Low-Molecular-Weight Organic Acids and Organic Carbon of Taiwan Red Cypress, Peacock Pine, and Moso Bamboo in a Temperate Rain Forest
}

\author{
Ya Nan Wang \\ School of Forestry and Resource Conservation, National Taiwan \\ University, Taipei, Taiwan \\ Ming Kuang Wang and Shun Yao Zhuang \\ Department of Agricultural Chemistry, National Taiwan University, \\ Taipei, Taiwan \\ Ta Chi Tu and Kai Yin Chiang \\ School of Forestry and Resource Conservation, National Taiwan \\ University, Taipei, Taiwan
}

\begin{abstract}
Low-molecular-weight organic acids (LMWOAs) derived from root exudates and complexed with available metals in the rhizosphere soils of Taiwan red cypress (Chamaeyparis formosensis, FRS), peacock pine (Cryptomeria japonica, JRS), and moso bamboo (Phyllostachys pubescens, PRS) were identified by gas chromatograph (GC). The fresh plants (i.e., leaves, stems, roots, and litters) and soil samples of those three vegetations were examined for their organic functional groups. This study focused on (1) assessing methods for processing LMWOAs in the rhizosphere soils and fresh plants by GC analysis and (2) determining the relative proportions of organic carbon $(\mathrm{C})$ functional groups in the three vegetations and fresh plant materials with ${ }^{13} \mathrm{C}$ nuclear magnetic resonance (NMR) analysis. The proportion of LMWOAs contents followed the order of PRS $>$ FRS $>$ JRS $>$ bulk soils. The recovery and spiking tests analyzed by GC showed good recovery $(>83.6 \%)$ and reproducibility of LMWOAs. The proportion of organic functional groups in the rhizosphere
\end{abstract}

Received 26 March 2004, Accepted 12 May 2006

Address correspondence to Ming Kuang Wang, Department of Agricultural Chemistry, National Taiwan University, Taipei 106, Taiwan. E-mail: mkwang@ntu. edu.tw 
and bulk soil quantified by ${ }^{13} \mathrm{C}$ NMR analysis followed the general order alkyl-C $>$ aromatic- $\mathrm{C}>\mathrm{O}$-alkyl- $\mathrm{C}>\mathrm{N}$-alkyl- $\mathrm{C}>$ phenolic- $\mathrm{C}>$ acetal- $\mathrm{C}>$ carboxyl- $\mathrm{C}$. The carbohydrates, hemicellulose, lignin, and cellulose contents obtained by ${ }^{13} \mathrm{C} \mathrm{NMR}$ analysis suggested that Phyllostachys pubescen $(P B)$ cannot easily be decomposed under the mountain forest soil environments.

Keywords: Bulk soils, ${ }^{13} \mathrm{C}$ nuclear magnetic resonance (NMR), gas chromatograph (GC), rhizosphere soils, root exudates

\section{INTRODUCTION}

Rhizosphere is defined as that volume of soil affected by the presence of the roots of growing plants. The vegetation change may be related to biological, physical, and chemical properties of soils. A multiple of compounds are released into the rhizosphere of plants grown in soil, most of which are normal plant constituents derived from photosynthesis and other plant processes (Uren 2001). The relative and absolute amounts of lowmolecular-weight organic acids (LMWOAs) produced by plant roots in the form of exudates vary with the plant species, cultivar, age of plant, and environmental conditions including soil properties (Robert and Berthelin 1986).

The biological activities of microorganisms in the rhizosphere mediate the solubility to a large degree. The complexities of the interactions among soil, microorganisms, and plants are needed to study these highly sophisticated biological systems (Jones and Darrah 1994; Manthey et al. 1994; Chiu et al. 2002). The soil that remained adhered to the roots after gentle shaking was sampled as rhizosphere soils according to operational definition (Lynch 1990). The root exudation takes place primarily from fine roots near root tips, which are usually closely spaced in the A soil horizon. A bulk soil was sampled from a central location of about $50 \mathrm{~cm}$ in distance from the main root surface between these trees.

Conventional characterization of soil organic matter (SOM) previously used alkaline and acid solutions to extract SOM, which were tightly bound to soil inorganic colloids, resulting in soil aggregation (Stevenson 1994). In recent decades, advances in gas chromatograph (GC) as well as cross-polarization and magic angle spinning ${ }^{13} \mathrm{C}$ solid-state nuclear magnetic resonance $\left({ }^{13} \mathrm{C}\right.$ NMR) have assisted in the study of LMWOAs and SOM components (Oades 1993). The cross-polarization and magic angle spinning (CPMAS) solid-state ${ }^{13} \mathrm{C}$ NMR is a nondestructive method that can help characterize SOM in mineral and organic soils (Preston et al. 1989, 1990, 1994). Both $\mathrm{GC}$ and ${ }^{13} \mathrm{C}$ NMR analytical methods are useful tools for studying root exudates of various tree species and transformation of SOM. 
Taiwan red cypress (Chamaeyparis formosensis, $C F$ ), peacock pine (Cryptomeria japonica, CJ), and moso bamboo (Phyllostachys pubescens, $P B)$ are major tree vegetations widely distributed in the middle or high elevation of Taiwan. To clarify root exudate productions, transformation of SOM in these vegetations are important for the sustainable managements of forestry. Therefore, this study focused on (1) assessing methods for processing LMWOAs by GC analysis and (2) determining the relative proportions of organic $\mathrm{C}$ functional groups in the three vegetations and fresh plant materials with ${ }^{13} \mathrm{C}$ NMR analysis.

\section{MATERIALS AND METHODS}

\section{Study Sites}

Three study blocks were located within (A) $C F$, (B) $C J$, and (C) $P B$ vegetations. The study sites were located on Si-tou, Forest Experimental Station of National Taiwan University, in central Taiwan, with an annual precipitation of about $2057 \mathrm{~mm}\left(23^{\circ} 40^{\prime} \mathrm{N}, 120^{\circ} 47^{\prime} \mathrm{E}\right)$. The average annual temperature is $17^{\circ} \mathrm{C}$. There are three sites in each block of $C F, C J$, and $P B$ vegetations with elevation of $1150 \mathrm{~m}$. Rhizosphere and bulk soils $(0-15 \mathrm{~cm})$ of three species of trees were sampled in a triplicates. Sample collections were made in completed random design (CRD) at each block. Fresh roots, stems, leaves, and litters of these trees were also collected as comparison. The samples were immediately preserved with dry ice. Soil and plant materials were ground, passed through a sieve $(<2 \mathrm{~mm})$, and then stored in a deep freezer at $-24^{\circ} \mathrm{C}$.

\section{Soil Physical and Chemical Properties}

Soil $\mathrm{pH}$ of the samples was measured in distilled water and $0.1 \mathrm{M} \mathrm{KCl}$ solution ( soil-solution $=1: 5)$. Concentrations of organic $\mathrm{C}$ and nitrogen $(\mathrm{N})$ of the soils were determined by a Carlo Erba CHN analyzer. Cation-exchange capacity (CEC) of the soils was determined by the conventional $\mathrm{NH}_{4} \mathrm{OAc}$ method (Gillman 1979). Exchangeable cations in supernatants were extracted by $1 M$ ammonium acetate ( $\mathrm{pH}$ 7.0) solutions. Concentrations of exchangeable sodium $(\mathrm{Na})$ and potassium $(\mathrm{K})$ were determined by flame photometer. Magnesium $(\mathrm{Mg})$ and calcium $(\mathrm{Ca})$ were determined by atomic absorption (AA) spectrometry (Hitachi 180-30). The dispersed soils were separated into clay, silt, and sand fractions by sedimentation and centrifugation (Jackson 1979). Soils were classified as silty loam, mixed, mesic, humic, Dystrudepts (Soil Survey Staff 2003). 


\section{Determination of Low-Molecular-Weight Organic Acids in Root Exudates by Gas Chromatograph}

Gas chromatography analysis of methylated dicarboxylic acids was employed using an Agilent 6850 series GC system, equipped with flame ionization detector aid as J\&W Scientific GC column $(0.25 \mathrm{~mm} \times 30 \mathrm{~m}, 0.1 \mathrm{~mm}$, i.d. $)$. The injector, column, and detector temperatures were 200,125 , and $200^{\circ} \mathrm{C}$, respectively. Helium was used as the carrier gas at a flow rate of $59.6 \mathrm{~mL}$ $\min ^{-1}$. The chromatograms were integrated by GC chemostatic Rev. A. 08103 software.

Standards for the LMWOAs (oxalic, malonic, succinic, fumaric, and maleic) were obtained from Sigma Chemical Co., whereas methanol and chloroform used for sample preparation were analytical-grade reagents. Methylmalonic acid, not found in root exudates of $C F, C J$, and $P B$, was used as an internal standard and added both standard mixtures and samples before methylation.

\section{Acid Extraction and Concentration from Roots, Stems, Leaves, and Litter Exudates, Rhizosphere and Bulk Soils}

Fresh materials corresponding to $1 \mathrm{~g}$ of dry weight of ground roots, stems, leaves, and litters and $15 \mathrm{~g}$ of soils were extracted in a $250-\mathrm{mL}$ centrifuge tube for extractions with $20 \mathrm{~mL}$ of $0.5 \mathrm{M} \mathrm{HCl}$ in methanol $(\mathrm{MeOH}) 1: 1$ ratio after being shaken for $1 \mathrm{~h}$ and then centrifuged at $10,000 \times \mathrm{g}$. The detailed methylation, separation and injection into GC column, and recovery test of samples were described by Chen et al. (2001).

\section{Sample Stability}

LMWOAs of derived samples were quite stable when samples were stored under refrigeration and transported to the laboratory in dry ice. Samples analyzed after 1 month of storage in the freezer $\left(-24^{\circ} \mathrm{C}\right)$ showed no signs of decomposition.

\section{CPMAS ${ }^{13} \mathrm{C}$ Nuclear Magnetic Resonance Analysis}

Organic functional groups of ground fresh roots, stems, leaves, litters, and soils were examined by CPMAS ${ }^{13} \mathrm{C}$ nuclear magnetic resonance (NMR) spectroscopy (Oades 1995) using a Bruker MSL-200 NMR instrument. Samples were spun at the magic angle in the boron nitride rotor with a Kel-F cap. Data acquisition conditions were spectrometer frequency, $50.33 \mathrm{MHz}$; spinning speed, $3500 \mathrm{~Hz}$; contact time, $1 \mathrm{~ms}$; and pulse delay 
time, $1 \mathrm{~s}$. The NMR spectra were divided into the following chemical shift regions: alkyl-C (0-45 ppm), N-alkyl-C (46-65 ppm), O-alkyl-C (65$90 \mathrm{ppm})$, acetal-C (90-110 ppm), aromatic-C (110-140 ppm), phenolic-C (140-160 ppm), and carboxyl-C (160-200 ppm) (Preston et al. 1990). Areas of the chemical shifts measured by cutting and weighting were expressed as percentages of total area (relative intensity) (Preston et al. 1990; Chen et al. 2001).

\section{RESULTS AND DISCUSSION}

The pH of bulk soils (FBS, JBS, and PBS) was higher than that of FRS, JRS, and PRS rhizosphere soils owing to organic acid exudates. The $\mathrm{pH}$ values of the three trees' rhizosphere soils showed no significant differences. All sample textures were silty loam. Cation-exchange capacity (CEC) and sum of exchangeable cations showed the trend as PRS $>$ JRS $>$ FRS $>$ PBS $>$ FBS $>$ JBS (Table 1). Organic $\mathrm{C}$ and total $\mathrm{N}$ contents showed a similar trend as soil $\mathrm{pH}$ (Tu 2002).

\section{Determination of Low-Molecular-Weight Organic Acids}

The five LMWOAs investigated in this study required more than $10 \mathrm{~min}$ for elution, making GC monitoring of the organic acid contents in solutions very fast and efficient. Each sample was injected at a 15-min interval, and methylation of standard mixtures yielded clean chromatograms with no artifacts formed. The results were similar to those reported by Chen et al. (2001).

Recovery of all LMWOAs was more than $83.6 \%$ (Table 2). The fumaric and maleic acids showed higher recovery percentages. The recovery of acids from the extraction/concentration and methylation procedure was examined by spiking the FRS, JRS, and PRS with $100 \mu \mathrm{g}$ of selected acids. Good recovery and reproducibility were obtained for the saturated dicarboxylic, oxalic, malonic, and succinic acids (Lilieholm et al. 1992). It has been reported that the methylation of unsaturated dicarboxylic acids may be accompanied by undesirable side reactions, and cis-trans isomerization (Moghimi et al. 1978). Methodology evaluation demonstrated that the method developed in this study was accurate and precise. The LMWOAs in various rhizosphere soils of FRS, JRS, and PRS are shown in Table 3. The proportion of oxalic acid contents followed the order PRS $>$ FRS $>$ JRS $>$ bulk soils, with significant differences $(\mathrm{p}<0.05)$. On the other hand, malonic, fumaric, and succinic acids showed the same trends as oxalic acid concentrations.

LMWOAs in the fresh formosensis roots (FFR); twigs and leaves (FFS); fresh japonica roots (FJR) and twigs and leaves (FJS); fresh pubescens roots 
Table 1. Selected soil physical and chemical properties of Chamaecyparis formosensis, Cyrptomeria japonica, and Phyllostacys pubescens rhizosphere and bulk soils

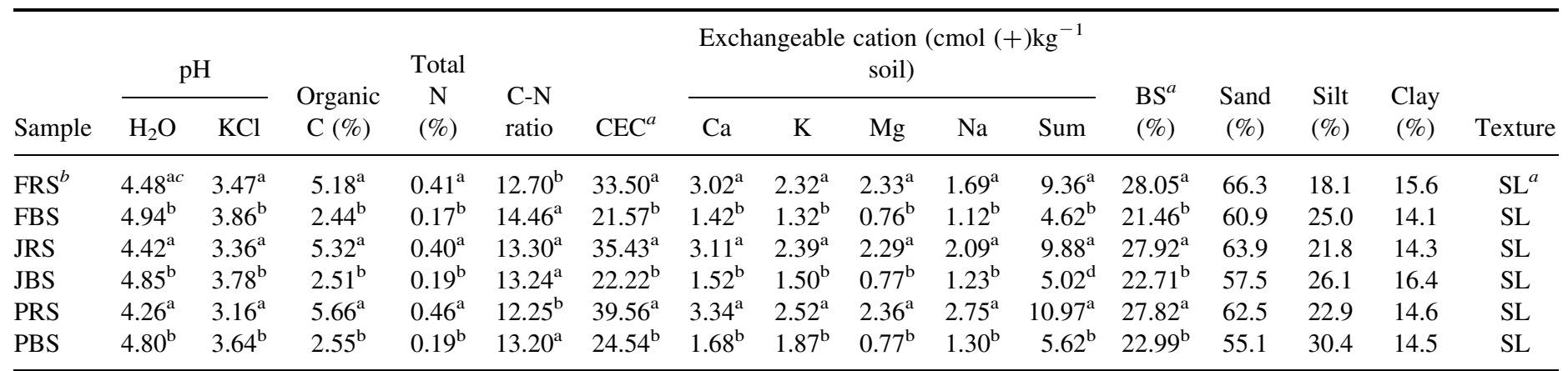

${ }^{a} \mathrm{CEC}$ : cation exchangeable capacity; BS: base saturation; SL: sandy loams.

${ }^{b}$ FRS: Chamaecyparis formosensis rhizosphere soil; FBS: Chamaecyparis formosensis bulk soil; JRS: Cryptomeria japonica rhizosphere soil; JBS: Cryptomeria japonica bulk soil; PRS: Phyllostachys pubescens rhizosphere soil; PBS: Phyllostachys pubescens bulk soil.

${ }^{c}$ The number followed by the same letter is not significantly different $(\mathrm{p}<0.05)$ as determined by Duncan's multiple range test. 
Table 2. Recovery of added spike of low-molecular-weight dicarboxylic acids of rhizosphere soils by $\mathrm{HCl} / \mathrm{MeOH}$ extraction as determined by GC

\begin{tabular}{|c|c|c|c|c|c|c|c|c|c|}
\hline \multirow[b]{2}{*}{$\operatorname{Acid}^{a}$} & \multicolumn{3}{|c|}{ Amount found in unspiked samples $(\mu \mathrm{g})$} & \multicolumn{3}{|c|}{ Amount found in spiked samples $(\mu \mathrm{g})$} & \multicolumn{3}{|c|}{ Recovery $\pm \mathrm{SD}(\%)$} \\
\hline & FRS & JRS & PRS & FRS & JRS & PRS & FRS & JRS & PRS \\
\hline Malonic & $46.1 \pm 2.7^{\mathrm{b}}$ & $37.6 \pm 2.2^{\mathrm{b}}$ & $92.3 \pm 1.6^{\mathrm{a}}$ & $134 \pm 3.5^{\mathrm{b}}$ & $128 \pm 5.9^{\mathrm{b}}$ & $183 \pm 1.7^{\mathrm{a}}$ & $88.1 \pm 3.0$ & $89.9 \pm 3.2$ & $91.0 \pm 3.1$ \\
\hline Fumaric & $11.0 \pm 1.7^{\mathrm{a}}$ & $9.9 \pm 1.8^{\mathrm{a}}$ & $12.7 \pm 8.1^{\mathrm{a}}$ & $103 \pm 6.8^{\mathrm{a}}$ & $102 \pm 2.3^{\mathrm{a}}$ & $105 \pm 4.7^{\mathrm{a}}$ & $91.8 \pm 1.3$ & $92.2 \pm 1.5$ & $92.6 \pm 4.0$ \\
\hline Succinic & $89.2 \pm 4.7^{\mathrm{a}}$ & $81.1 \pm 6.0^{\mathrm{a}}$ & $111 \pm 5.2^{\mathrm{a}}$ & $179 \pm 7.2^{\mathrm{a}}$ & $172 \pm 2.7^{\mathrm{a}}$ & $200 \pm 5.4^{\mathrm{a}}$ & $90.2 \pm 3.6$ & $91.3 \pm 3.7$ & $89.8 \pm 3.8$ \\
\hline
\end{tabular}

${ }^{a} 100 \mu \mathrm{g}$ of each acid added to $1 \mathrm{~g}$ of soil $(\mathrm{n}=3)$.

${ }^{b}$ Data are expressed as mean \pm SD. Averages followed by the same letter are not significantly different $(p<0.05)$ as determined by least significant difference (LSD) test.

${ }^{c}$ Not detectable $\left(\mathrm{MDL}<1 \mathrm{mg} \mathrm{kg}^{-1}\right)$.

Note: FRS: Chamaecyparis formosensis rhizosphere soil; JRS: Cryptomeria japonica rhizosphere soil; PRS: Phyllostachys pubescens rhizosphere soil. 
Table 3. Low-molecular-weight organic acids in FRS, JRS, PRS, FBS, JBS, and PBS

\begin{tabular}{llcccc}
\hline & \multicolumn{4}{c}{ Organic acid concentration $\left(\mathrm{mg} / \mathrm{kg}^{-1}\right.$ dry weight of soil) } \\
\cline { 2 - 6 } Sample $^{a}$ & Oxalic acid & $\begin{array}{c}\text { Malonic } \\
\text { acid }\end{array}$ & $\begin{array}{c}\text { Fumaric } \\
\text { acid }\end{array}$ & $\begin{array}{c}\text { Succinic } \\
\text { acid }\end{array}$ & $\begin{array}{c}\text { Maleic } \\
\text { acid }\end{array}$ \\
\hline FRS & $54.4 \pm 10.1^{\mathrm{b} b}$ & $7.8 \pm 1.4^{\mathrm{a}}$ & $1.9 \pm 0.6^{\mathrm{b}}$ & $18.6 \pm 5.9^{\mathrm{b}}$ & - \\
FBS & $30.2 \pm 10.3^{\mathrm{c}}$ & $2.7 \pm 1.0^{\mathrm{b}}$ & $0.8 \pm 0.5^{\mathrm{c}}$ & $8.0 \pm 3.2^{\mathrm{c}}$ & - \\
JRS & $44.5 \pm 11.9^{\mathrm{b}}$ & $5.9 \pm 1.2^{\mathrm{a}}$ & $1.4 \pm 0.4^{\mathrm{b}}$ & $14.6 \pm 5.5^{\mathrm{b}}$ & - \\
JBS & $20.7 \pm 10.3^{\mathrm{b}}$ & $2.3 \pm 1.2^{\mathrm{b}}$ & $0.5 \pm 0.3^{\mathrm{c}}$ & $7.2 \pm 3.8^{\mathrm{c}}$ & - \\
PRS & $63.2 \pm 8.9^{\mathrm{a}}$ & $11.8 \pm 2.9^{\mathrm{a}}$ & $2.6 \pm 0.8^{\mathrm{a}}$ & $23.1 \pm 8.7^{\mathrm{a}}$ & - \\
PRS & $30.8 \pm 13.1^{\mathrm{c}}$ & $4.3 \pm 1.4^{\mathrm{b}}$ & $1.1 \pm 0.5^{\mathrm{c}}$ & $9.2 \pm 3.0^{\mathrm{c}}$ & - \\
\hline
\end{tabular}

${ }^{a}$ FRS: Chamaecyparis formosensis rhizosphere soil; FBS: Chamaecyparis formosensis bulk soil; JRS: Cryptomeria japonica rhizosphere soil; JBS: Cryptomeria japonica bulk soil; PRS: Phyllostachys pubescens rhizosphere soil; PBS: Phyllostachys pubescens bulk soil.

${ }^{b}$ Data are expressed as mean \pm SD. Averages followed by the same letter are not significantly different $(\mathrm{p}<0.05)$ as determined by least significant difference (LSD) test.

${ }^{c}$ Not detectable (MDL $<1 \mathrm{mg} \mathrm{kg}^{-1}$ ).

(FPR) and twigs and leaves (FPS) were identified on the basis of retention time by GC analysis (Table 4). The reproducibility of retention time was good, as indicated by the recovery test of more than $83.6 \%$. High oxalic acid contents were present in FFS $\left(2400 \pm 1.2 \mathrm{mg} \mathrm{kg}^{-1}\right)$, FJS $\left(1610 \pm 2.4 \mathrm{mg} \mathrm{kg}^{-1}\right)$, and FPS $\left(2530 \pm 1.1 \mathrm{mg} \mathrm{kg}^{-1}\right)$. High malonic acids were also present in FFS $\left(1540 \pm 4.4 \mathrm{mg} \mathrm{kg}^{-1}\right)$ and FJS $\left(1060 \pm 7.9 \mathrm{mg} \mathrm{kg}^{-1}\right)$ and showed significant differences between FFS and FJS. The succinic acid contents in FFS and FJS showed a trend similar to malonic acid. The amounts of LMWOAs in fresh twigs and leaves were greater than those in fresh roots. The amounts of malonic and succinic acids in FFS were greater than those in FJS and FPS. There were low concentrations of furmaric acid present in FPR $\left(78.0 \pm 1.0 \mathrm{mg} \mathrm{kg}^{-1}\right)$ and FPS $\left(40.4 \pm 3.2 \mathrm{mg} \mathrm{kg}^{-1}\right)$. No maleic acids were present in any rhizosphere soils or plant tissues (Tables 3 and 4), respectively.

\section{Nature of Organic Matter}

The ${ }^{13} \mathrm{C}$ NMR analysis of soil organic matter (SOM) and organic carbon in FRS, JRS, PRS, and PBS can be classified into seven groups (Figure 1A). The concentrations of these organic functional groups in the rhizosphere soils followed the general trend alkyl-C $>$ aromatic-C $>$ O-alkyl-C $>$ $\mathrm{N}$-alkyl-C $>$ phenolic-C $>$ acetal-C $>$ carboxyl-C (Table 5). The N-alkyl-C, O-alkyl-C, and carboxyl-C contents in PBS were greater than these in FRS 
Table 4. Low-molecular-weight organic acids in plants

\begin{tabular}{|c|c|c|c|c|c|c|}
\hline Sample $^{a}$ & Oxalic acid & Malonic acid & Fumaric acid & Succinic acid & Maleic acid & Sum \\
\hline FFR & ${ }^{c} 280.3 \pm 1.3^{\mathrm{a}}$ & $82.6 \pm 8.1^{\mathrm{d}}$ & $-{ }^{d}$ & $60.8 \pm 1.6^{\mathrm{d}}$ & - & 423.7 \\
\hline FFS & $2400 \pm 1.2^{\mathrm{d}}$ & $1540 \pm 4.4^{\mathrm{a}}$ & - & $1320 \pm 1.0^{\mathrm{a}}$ & - & 5260 \\
\hline FJR & $188 \pm 2.7^{\mathrm{d}}$ & $56.6 \pm 2.2^{\mathrm{d}}$ & - & $41.2 \pm 1.2^{\mathrm{d}}$ & - & 285.8 \\
\hline FJS & $1610 \pm 2.4^{\mathrm{b}}$ & $1060 \pm 7.9^{b}$ & - & $898 \pm 5.0^{\mathrm{b}}$ & - & 3568 \\
\hline FPR & $980 \pm 2.3^{c}$ & $113 \pm 1.2^{\mathrm{c}}$ & $78.0 \pm 1.0^{\mathrm{a}}$ & $75.3 \pm 1.1^{\mathrm{d}}$ & - & 2796.3 \\
\hline FPS & $2530 \pm 1.1^{\mathrm{a}}$ & $93.6 \pm 6.6^{\mathrm{d}}$ & $40.4 \pm 3.2^{\mathrm{b}}$ & $233 \pm 4.7^{\mathrm{c}}$ & - & 1347 \\
\hline
\end{tabular}

${ }^{a}$ FFR: Chamaecyparis formosensis fresh root; FFS: Chamaecyparis formosensis fresh twig and leaf; JFR: Cryptomeria japonica fresh root; JFS: Cryptomeria japonica fresh twig and leaf; PFR: Phyllostachys pubescens fresh root; PFS: Phyllostachys pubescens fresh twig and leaf.

${ }^{b}$ Recovery $(>83.6 \%)$ of low-molecular-weight dicarboxylic acids from $\mathrm{HCl} / \mathrm{MeOH}$ extraction of plants as determined by $\mathrm{GC}$ after sample methylation.

${ }^{c}$ Data are expressed as mean \pm SD. Averages followed by the same letter are not significantly different $(p<0.05)$ as determined by least significant difference (LSD) test.

${ }^{d}$ Not detectable (MDL $<1 \mathrm{mg} \mathrm{kg}^{-1}$ ). 

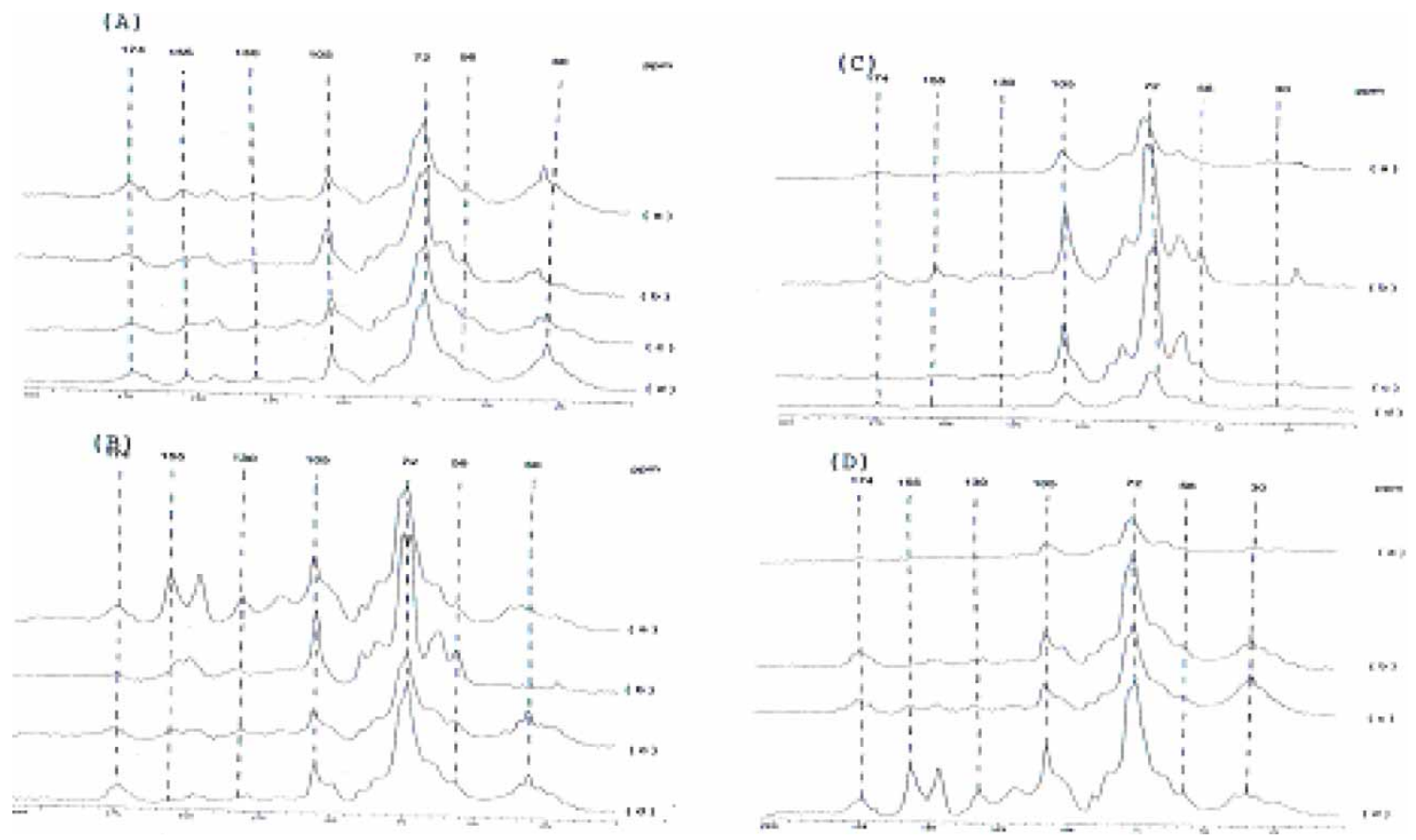

Figure 1. ${ }^{13} \mathrm{C}$ NMR analysis of soil organic matter (SOM) and organic C in (a) FRS, (b) JRS, (c) PRS, and (d) PBS can be classified into seven groups (1A). The distribution of organic functional groups in Chamaecyparis formosensis of (a) fresh leaves (FFL), (b) stems (FFS), (c) roots (FFR), and (d) litters (FL) (1B); Crytomeria japonica (a) fresh leaves (JFL), (b) stems (JFS), (c) roots (JFR), and (d) litters (JL) (1C); and Phyllostachys pubescens (a) fresh leaves (PFL), (b) stems (PFS), (c) roots (PFR), and (d) litters (PL) (1D). 
Table 5. Distribution (\%) of organic carbon functional groups in FRS, JRS, PRS, FBS, JBS, and PBS

\begin{tabular}{|c|c|c|c|c|c|c|c|}
\hline \multirow[b]{2}{*}{ Sample $^{a}$} & \multicolumn{7}{|c|}{ Functional group (\%) } \\
\hline & Alkyl-C & N-alkyl-C & O-alkyl-C & Acetal-C & Aromatic-C & Phenolic-C & Carboxyl-C \\
\hline FRS & $22.9 \pm 9.0^{\mathrm{a} b}$ & $12.4 \pm 1.8^{\mathrm{a}}$ & $13.7 \pm 2.0^{\mathrm{a}}$ & $11.3 \pm 2.1^{\mathrm{a}}$ & $18.3 \pm 8.4^{\mathrm{a}}$ & $12.5 \pm 2.7^{\mathrm{a}}$ & $8.9 \pm 2.9^{b}$ \\
\hline FBS & $10.3 \pm 6.1^{\mathrm{b}}$ & $6.3 \pm 1.9^{\mathrm{b}}$ & $5.3 \pm 1.2^{\mathrm{b}}$ & $7.5 \pm 3.7^{\mathrm{a}}$ & $15.3 \pm 7.3^{\mathrm{a}}$ & $10.5 \pm 3.7^{\mathrm{a}}$ & $7.5 \pm 3.6^{\mathrm{b}}$ \\
\hline JRS & $24.5 \pm 9.8^{\mathrm{a}}$ & $12.3 \pm 1.8^{\mathrm{a}}$ & $13.7 \pm 1.8^{\mathrm{a}}$ & $10.7 \pm 1.9^{\mathrm{a}}$ & $18.5 \pm 9.2^{\mathrm{a}}$ & $11.3 \pm 3.4^{\mathrm{b}}$ & $9.0 \pm 3.3^{\mathrm{b}}$ \\
\hline JBS & $11.4 \pm 3.7^{\mathrm{b}}$ & $5.2 \pm 1.4^{\mathrm{b}}$ & $4.7 \pm 1.3^{\mathrm{b}}$ & $6.3 \pm 1.1^{\mathrm{a}}$ & $14.7 \pm 2.7^{\mathrm{a}}$ & $8.3 \pm 4.5^{\mathrm{b}}$ & $7.3 \pm 4.5^{\mathrm{b}}$ \\
\hline PRS & $23.6 \pm 8.7^{\mathrm{a}}$ & $13.4 \pm 2.1^{\mathrm{a}}$ & $16.4 \pm 1.4^{\mathrm{a}}$ & $9.6 \pm 1.1^{\mathrm{a}}$ & $16.3 \pm 9.8^{\mathrm{a}}$ & $8.5 \pm 1.1^{\mathrm{b}}$ & $12.2 \pm 3.0^{\mathrm{b}}$ \\
\hline PBS & $17.0 \pm 8.3^{\mathrm{b}}$ & $6.4 \pm 1.0^{\mathrm{b}}$ & $17.1 \pm 1.3^{\mathrm{b}}$ & $7.2 \pm 1.0^{\mathrm{a}}$ & $13.0 \pm 8.8^{\mathrm{a}}$ & $7.3 \pm 3.3^{\mathrm{b}}$ & $18.7 \pm 3.5^{\mathrm{a}}$ \\
\hline
\end{tabular}

${ }^{a}$ FRS: Chamaecyparis formosensis rhizosphere soil; FBS: Chamaecyparis formosensis bulk soil; JRS: Cryptomeria japonica rhizosphere soil; JBS: Cryptomeria japonica bulk soil; PRS: Phyllostachys pubescens rhizosphere soil; PBS: Phyllostachys pubescens bulk soil.

${ }^{b}$ Data are expressed as mean \pm SD. Averages followed by the same letter are not significantly different $(\mathrm{p}<0.05)$ as determined by east significant difference (LSD) test. 
and JRS. High O-alkyl-C, aromatic-C, and phenolic-C and low N-alkly-C and acetal-C contents were present in bulk soils, indicating that the rate of SOM decomposition is slower than that of rhizosphere soils. The alkyl-C contents in rhizosphere soils were greater than those in bulk soils. The sources of alkyl-C were from root exudates and microbial resynthesis. Guggenberger et al. $(1994,1995)$ reported that monosaccharide is a major production of microbial resynthesis. Although the contents of organic $\mathrm{C}$ functional groups analyzed by NMR can be quantified from peak area with errors because of its peak overlap, it shows a reproducible trend (Malcolm 1989; Guggenberger et al. 1994, 1995; Oades 1995). Alkyl-C, N-alkyl-C, O-alkyl-C, and aromatic-C in rhizosphere soil samples of FRS, JRS, and PRS showed no significant differences, but phenolic-C and carboxyl-C did (Table 5).

The distribution of organic functional groups in Chamaecyparis formosensis fresh leaves (FFL), stems (FFS), roots (FFR), and litters (FL); Crytomeria japonica fresh leaves (JFL), stems (JFS), roots (JFR), and litters (JL); and Phyllostachys pubescens fresh leaves (PFL), stems (PFS), roots (PFR), and litters (PL) are shown in Table 6 and Figures 1(B), 1(C), and 1(D). The highest of O-alkyl-C (cellulose) contents were present in plant tissues of Phyllostachys pubescens. The amounts of O-alkyl-C and carboxyl-C in fresh leaves, stems, roots, and litters of the three tree species showed no significant differences. Lignin (aromatic-C and phenolic-C) contents of FL and JL are greater than those of Chamaecyparis formosensis and Crytomeria japonica plant tissues (Table 6). However, lignin concentrations in Phyllostachys pubescens litters (PL) showed no significant differences with PFL, PFS, and PFR. Hemicellulose (N-alkyl-C and acetal-C) showed the trend as follows: $\mathrm{FL}>(\mathrm{FFL}=\mathrm{FFS}=\mathrm{FFR})$. On the other hand, cellulose contents in FL showed the reverse trend. Carbohydrates contents (alkyl-C) in the leaves, stems, roots, and litters of these trees showed random distribution, but in general, it can be summarized as the following tendency: Chamaecyparis formosensis $>$ Crytomeria japonica $>$ Phyllostachys pubescens. Carboxyl-C concentrations showed a trend similar to alkyl-C (carboxydrates) concentrations. After decomposition, the components of microsynthesis carboxydrate, hemicellulose, and lignin tended to increase (Hatcher 1987). Chamaecyparis formosensis decomposes more easily than Crytomeria japonica and Phyllostachys pubescens. The cellulose (O-alkyl-C) contents in Phyllostachys pubescens plant tissues were greater than those of Crytomeria japonica and Chamaecyparis formosensis (Table 6). On the other hand, the sum of carbohydrates (alkyl-C), hemicellulose (N-alkyl-C and acetal-C), lignin (aromatic-C and phenolic-C), and carboxyl-C are also show the trend as Chamaecyparis formosensis (FFL of $64.5 \%$, FFS of $65.7 \%$, FFR of $64.0 \%$, and FL of 93.3\%) > Crytomeria japonica (JFL of $61.6 \%$, JFS of $56.2 \%$, JFR of $64.4 \%$ and JL of $65.1 \%$ ) $>$ Phyllostachys pubescens (PFL of $57.9 \%$, PFS of $53.2 \%$, PFR of $49.7 \%$, and PL of $62.1 \%$ ). The microbial resynthesis production of carbohydrates is a major component in the temperate rain forest soil environment with high annual precipitation. 
Table 6. Distribution (\%) of organic carbon functional groups in the plants

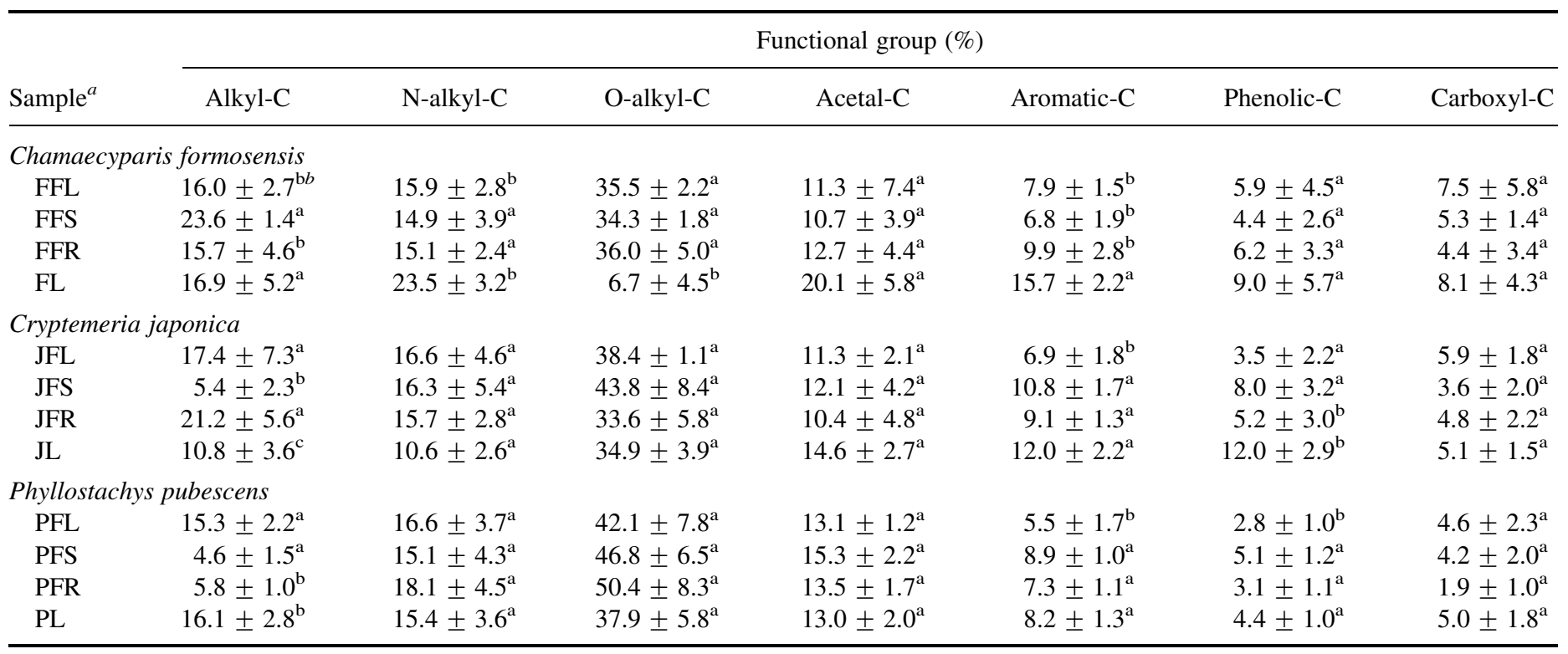

${ }^{a}$ FFL: Chamaecyparis formosensis leaves; FFS: Chamaecyparis formosensis stems; FFR: Chamaecyparis formosensis roots; FL: Chamaecyparis formosensis litters; JFL: Cryptemeria japonica leaves; JFS: Cryptemeria japonica stems; JFR: Cryptemeria japonica roots; JL: Cryptemeria japonica litters; PFL: Phyllostachys pubescens leaves; PFS: Phyllostachys pubescens stems; PFR: Phyllostachys pubescens roots; PL: Phyllostachys pubescens litters.

${ }^{b}$ Data are expressed as mean \pm SD. Averages followed by the same letter are not significantly different $(\mathrm{p}<0.05)$ as determined by least significant difference (LSD) test. 
In the temperate rain forest soil environments, the decomposition of Phyllostachys pubescens tissues is slower than that of Crytomeria japonica and Chamaecyparis formosensis. Hence, the cellulose contents (O-alkyl-C) in the PRS and PBS were greater than those in JRS and FRS (Table 5). However, the amounts of lignin (aromatic-C and phenolic-C) showed the reverse trend. The debris of the Phyllostachys pubescens is not easily decomposed under the mountain forest soil environment. Therefore, the PRS and PBS are the major organic $\mathrm{C}$ sources.

\section{CONCLUSIONS}

LMWOAs in rhizosphere soils analyzed by GC showed reproducible results and high recovery $(>83.6 \%)$. The ${ }^{13} \mathrm{C}$ NMR analysis could not accurately quantify its organic $\mathrm{C}$ functional groups owing to peak overlap. Quantitative organic $\mathrm{C}$ functional groups by ${ }^{13} \mathrm{C}$ NMR and the correlation among availability of metals, nutrients, and LMWOAs merit further study for plant growth.

\section{ACKNOWLEDGMENTS}

The authors gratefully acknowledge the financial support by the National Science Council, Taiwan, under projects NSC 85-2621-3002-017, 90-2313B-002-279, 90-2621-B-002-001-A10, and 91-2623-7-002-004.

\section{REFERENCES}

Chen, M.C., Wang, M.K., Chiu, C.Y., Huang, P.M., and King, H.B. (2001) Determination of low molecular weight dicarboxylic acids and organic functional groups in rhizosphere and bulk soils of Tsuga and Yushania in a temperate rain forest. Plant and Soil, 231: 37-44.

Chiu, C.Y., Wang, M.K., Hwong, J.L., and King, H.B. (2002) Physical and chemical properties in rhizosphere and bulk soils of Tsuga and Yushania in a temperate rain forest. Communications in Soil Science and Plant Analysis, 33 (11-12): 1723-1735.

Gillman, G.P. (1979) A proposed method for the measurement of exchange properties of highly weathered soils. Australian Journal Soil Research, 17: 129-139.

Guggenberger, G., Christensen, B.T., and Zech, W. (1994) Land-use effects on composition of organic matter in particle-size separate of soils, I: Lignin and carbohydrate signature. European Journal Soil Science, 45: 449-458.

Guggenberger, G., Zech, W., Haumaier, L., and Christensen, B.T. (1995) Landuse effects on composition of organic matter in particle-size separate of soils II: CPMAS and solution ${ }^{13} \mathrm{NMR}$ analysis. European Journal Soil Science, 46: 147-158.

Hatcher, P.G. (1987) Chemical structure studies of natural lignin dipolar dephasing solid-state ${ }^{13} \mathrm{C}$ nuclear magnetic resonance. Organic Geochemistry, 11: 31-39. 
Jackson, M.L. (1979) Soil Chemical Analysis, Advanced Course, 2nd ed; University of Wisconsin: Madison, Wisc., 479.

Jones, D.L. and Darrah, P.R. (1994) Role of root derived organic acids in the mobilization of nutrients from the rhizosphere. Plant and Soil, 166: 247-257.

Lilieholm, B.C., Dudley, L.M., and Jurinak, J.J. (1992) Oxalate determination in soils using ion chromatography. Soil Science Society of America Journal, 56: 324-326.

Lynch, J.M. (1990) Soil Rhizosphere; John Wiley \& Sons: New York;

Malcolm, R.L. (1989) Applications of solid-state ${ }^{13} \mathrm{C}$ NMR spectroscopy to geochemical studies of humic substances. In Humic Substances II; Hayes, M;H.B., MacCarthy, P., Malcolm, R.L., and Kafkafi, U. (eds.), John Wiley \& Sons: New York, 339-372.

Manthey, J.A., Crowley, D.E., and Luster, D.G. (1994) Biochemistry of Metal Micronutrients in the Rhizosphere; Lewis Publishers: Boca Raton, Fl., 373.

Moghimi, A., Tate, M.E., and Oades, J.M. (1978) Characterization of rhizosphere products especially 2-keto-gluconic acid. Soil Biological Biochemistry, 10: $283-287$.

Oades, J.M. (1993) The role of biology in the formation, stabilization and degradation of soil structure. Geoderma, 56: 377-400.

Oades, J.M. (1995) Recent advances in organomineral interactions: Implications for carbon cycling and soil structure. In Environmental Impact of Soil Component Interactions; Huang, P.M., Bollag, J.M., McGill, W.B., and Page, A.L. (eds.), CRC Press/Lewis Publishers: Boca Raton, Fl., 119-134.

Preston, C.M., Schnitzer, M., Lévesque, M., Mathur, S.P., Dinel, S.P., and Dudley, R.L. (1989) Carbon-13 NMR and chemical characterization of particle-size separates of peat differing in degree of decomposition. Organic Geochemistry, 14: 393-403.

Preston, C.M., Sollins, P., and Sayer, B.G. (1990) Changes in organic components for fallen $\operatorname{logs}$ in old-growth Douglas-fir forests monitored by ${ }^{13} \mathrm{C}$ nuclear magnetic resonance spectroscopy. Canadian Journal Forestry Research, 20: 1382-1391.

Preston, C.M., Hempfling, R., Schulten, H.-R., Schnitzer, M., Trofymow, J.A., and Alelson, D.E. (1994) Characterization of organic matter in a forest soil of coastal British Columbia by NMR and pyrolysis field ionization mass spectroscopy. Plant and Soil, 158: 69-82.

Robert, M. and Berthelin, J. (1986) Role of biological and biochemical factors in soil mineral weathering. In Interaction of Soil Minerals with Natural Organics and Microbes; Huang, P.M. and Schnitzer, M. (eds.), special publication no. 17, SSSA: Madison, Wisc., 453-495.

Soil Survey, Staff. (2003) Key Soil Taxonomy, 9th ed; United States Department of Agriculture and Soil Conservation Service: Washington, D.C.

Stevenson, F.J. (1994) Humus Chemistry; John Wiley \& Sons, Inc: New York, 496;

Szmigielska, A.M., Van Rees, K.C.L., Cieslinski, C., Huang, P.M., and Knott, D.R. (1995) Determination of low molecular weight dicarboxylic acids in root exudates by gas chromatography. Journal of Agricultural Food Chemistry, 43: 956-959.

Tu, T.A. (2002) Low molecular weight organic acids and ${ }^{13} \mathrm{C}$ nuclear magnetic spectroscopy analyses of Chamaecyparis formosensis, Cryptomeria japonica and phyllostachys pubescen rhizosphere and bulk soils at Chi-Tou Region. Master's thesis, National Taiwan University: Taipei, Taiwan, 66.

Uren, N.C. (2001) Types, amounts, and possible functions of compounds released into the rhizosphere by soil-grown plants. In The Rhizosphere; Pinton, R;, Varanini, Z., and Nannipieri, P. (eds.), Marcel Dekker, Inc: New York, 19-40. 